University of Louisville

ThinkIR: The University of Louisville's Institutional Repository

Electronic Theses and Dissertations

$5-2021$

\title{
Harmful algal blooms in the Ohio river: spatial and temporal differences.
}

Bevin Hardy

University of Louisville

Follow this and additional works at: https://ir.library.louisville.edu/etd

Part of the Biology Commons

\section{Recommended Citation}

Hardy, Bevin, "Harmful algal blooms in the Ohio river: spatial and temporal differences." (2021). Electronic Theses and Dissertations. Paper 3652.

https://doi.org/10.18297/etd/3652

This Master's Thesis is brought to you for free and open access by ThinkIR: The University of Louisville's Institutional Repository. It has been accepted for inclusion in Electronic Theses and Dissertations by an authorized administrator of ThinkIR: The University of Louisville's Institutional Repository. This title appears here courtesy of the author, who has retained all other copyrights. For more information, please contact thinkir@louisville.edu. 


\title{
HARMFUL ALGAL BLOOMS IN THE OHIO RIVER: SPATIAL AND TEMPORAL DIFFERENCES
}

\author{
By \\ Bevin Hardy \\ B.S., University of Tennessee - Knoxville, 2018 \\ M.S., University of Louisville, 2021 \\ Thesis \\ Submitted to the Faculty of the \\ Graduate School of the University of Louisville \\ in Partial Fulfillment of the Requirements \\ for the Degree of
}

Masters of Science

in Interdisciplinary Studies: Concentration in Sustainability

Interdisciplinary Studies

University of Louisville

Louisville, Kentucky

May 2021 

THE HARMFUL ALGAL BLOOMS IN THE OHIO RIVER: SPATIAL AND TEMPORAL DIFFERENCES

By

Bevin Hardy

A Thesis Approved on

April 5, 2021

By the following Thesis Committee

Tamara Sluss

C. Andrew Day

Deborah Yoder-Himes 


\section{ACKNOWLEDGEMENTS}

I would like to thank Dr. Tamara Sluss for accepting me into my program and providing me with wisdom and guidance throughout my thesis. I would also like to thank Dr. Deborah Yoder-Himes for her guidance and for allowing me to use her lab space to store and test my samples. Additionally, I would like to thank Dr. Christopher Day for serving on my committee and providing feedback. Lastly, I would like to thank my partner for their support throughout this research project and master's program, and their help with my statistical analysis. Lastly, I would like to thank my friends and family for their support and encouragement throughout my time at the University of Louisville. 


\section{ABSTRACT \\ HARMFUL ALGAL BLOOMS IN THE OHIO RIVER: SPATIAL AND TEMPORAL DIFFERENCES}

Bevin Hardy

April 5, 2021

The frequency of harmful algal blooms (HABs) has been increasing across the globe, especially in river ecosystems. Although more common in lakes, more HABs have been reported in rivers in the past decade, particularly in the Ohio River. In 2019, a HAB stretched 200 to 300 miles throughout the Ohio River from September to October. Samples were collected for the duration of the 2019 bloom (August-October) in the McAlpine Pool in Louisville, KY to compare microcystis toxin (microcystin) concentrations on a temporal and spatial scale. Different habitats (bay, creek, river) were sampled throughout the bloom, and two additional sampling days, one in September and one in October, were taken from a boat in various habitats throughout the channel of the river. Wind and temperature were also documented for each sample. ELISA kits were utilized to determine the presence and concentration of microcystin. There was some significance spatially and temporally, however, more samples are needed to draw these conclusions. 


\section{TABLE OF CONTENTS}

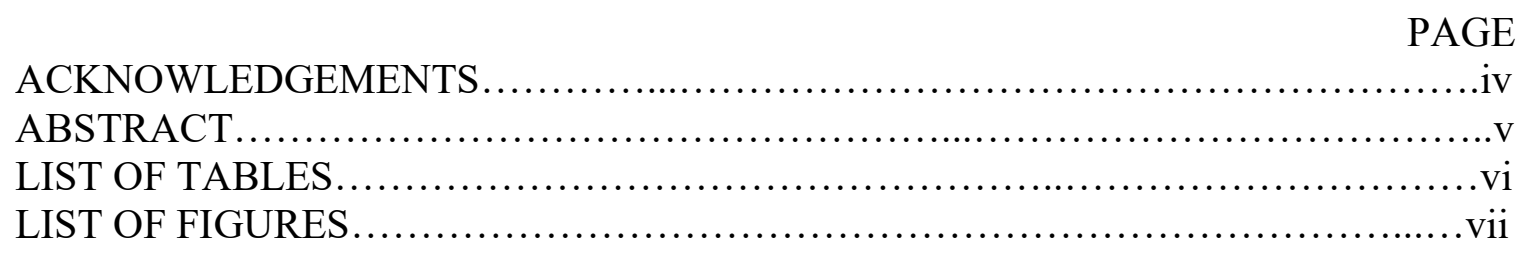

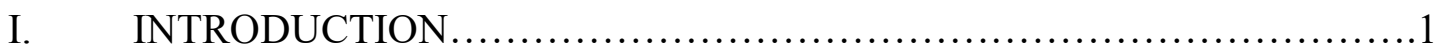

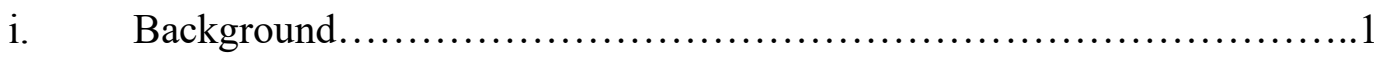

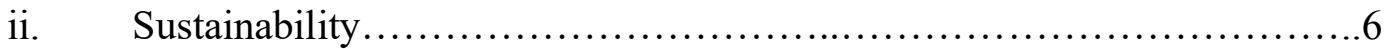

Environment.........................................

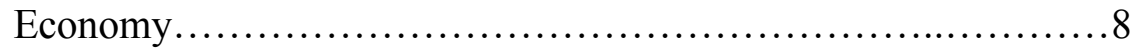

Social Equity.......................................... 10

iii. $\quad$ Purpose and Hypothesis.........................................11

Research Hypotheses...................................11

II. METHODS AND MATERIALS .................................... 14

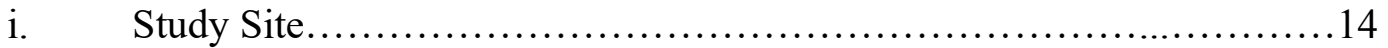

ii. Methods.................................................... 18

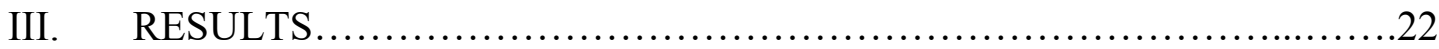

i. Continuous Sampling Days.....................................22

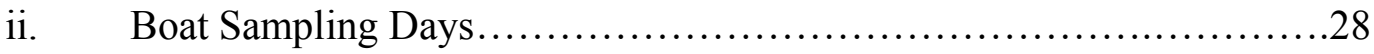

IV. DISCUSSION .................................................... 31

V. CONCLUSION ..................................................

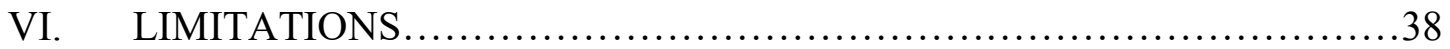




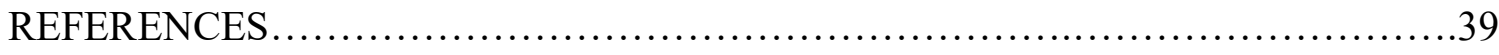

CURRICULUM VITA........................................................43 


\section{LIST OF TABLES}

TABLE

PAGE

1. P-values of fixed effects from linear fixed-effects model for each sampling date.....26

2. T-Test results from direct habitat comparisons for each sampling date..............27

3. P-values of fixed effects from linear fixed-effects model for each boat sampling

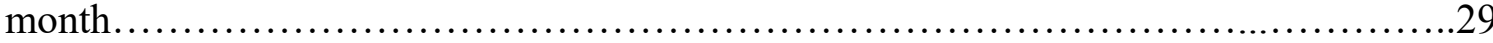




\section{LIST OF FIGURES}

FIGURE

PAGE

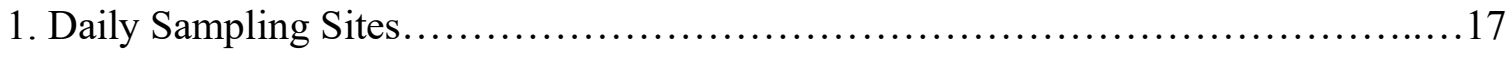

2. Boat Sampling Sites........................................................ 18

3. Average Toxin Concentrations Over Time in Each Habitat..........................23

4. Average Toxin Concentration Per Week (August-October)... ....................23

5. Maximum Toxin Concentration for Each Sampling Date.........................24

6. Minimum Toxin Concentration for Each Sampling Date..........................24

7. Average Toxin Concentration for Each Sampling Date...........................25

8. Box Plot for Toxin Concentrations for Each Habitat..............................2 27

9. Box Plot for Toxin Concentrations for Boat Sampling Days.......................29

10. Average Toxin Concentration at Each Sampling Site........................... 30

11. Average Toxin Concentration Difference between Habitats and Months.............30 


\section{CHAPTER I: INTRODUCTION}

Harmful algal blooms (HAB) have become a global phenomenon and demand attention from the general public and academic community to understand their intricacies and develop, or improve, management practices. This phenomenon has now spread to every continent, including Antarctica, and is calling for more research to understand its complexity in a variety of environments (Clark et al., 2017). HABs have been increasing in frequency and distribution over the past few decades, which has heightened concern of their impacts, specifically, on the environment, economy, and social equity. Water sources are an integral part to many systems, and if these valuable resources become contaminated through HABs, they have the potential to have far reaching consequences. This research attempts to enhance the understanding of HABs in large rivers and the connected water systems. This research is imperative as it can provide crucial information for potential management strategies for future HABs, specifically in large river systems.

i. Background

Despite the damage caused by HABs, they are a naturally occurring phenomenon created by algal communities vital to numerous environments. Algal communities are essential components in various ecosystems in waterbodies along the freshwater to marine continuum. These algal communities are comprised of phytoplankton which are 
critical to water ecosystems, even in large rivers. It was originally thought that large rivers did not provide a compatible environment to host phytoplankton, however, they provide a suitable habitat for a rich community of phytoplankton (Wehr \& Thorp, 1997). The vast array of modifications made to many large rivers have created favorable conditions for phytoplankton to inhabit, specifically through channelization and the creation of navigational dams. These modification reduce turbidity and downstream loss in the pools throughout dammed rivers, which allow phytoplankton to utilize the increased amount of light penetrating through the water column to flourish and multiply (Wehr \& Thorp, 1997). These favorable conditions become problematic when algal colonies proliferate rapidly to form a harmful algal bloom (HAB), depleting oxygen from the aquatic ecosystem and releasing toxins into the environment (Gatz \& Library of Congress. Congressional Research, 2018).

These blooms are classified as harmful because the algal colonies can accelerate eutrophication and emit toxins in an ecosystem (Gilbert \& Burford, 2017). Eutrophication is a naturally occurring process, however, it normally takes hundreds or thousands of years to occur (Anderson et al., 2002). Through anthropogenic influences, such as nutrient loading, alteration of water habitats, and climate change, this process has been accelerating rapidly and is now classified as cultural eutrophication or hypereutrophy (Carmichael, 2008). This process has been well-documented in European countries in most large rivers, and there is an extensive record of eutrophication accredited to human disturbance and pollution (Wehr \& Descy, 1998). In a study by Wehr and Descy (1998), it was observed that phytoplankton densities increased 10-fold in the Danube River in the 1970s, mainly attributed to the human alteration of river structures, which decreased 
turbidity and increased light exposure to algal communities. Eutrophication and HABs are less documented in the U.S., however, there has been more attention towards HABs because of the increase in their frequency and duration in major water systems across the country.

In the U.S. especially, HABs are better documented in coastal waters and lakes, with little attention to large rivers. Even though HABs can occur in virtually any aquatic ecosystem, the dynamics of the bloom are significantly different between each ecosystem and water type (Wells et al., 2015). For example, in lakes, nutrient loading is the primary driver for HABs, whereas, in rivers light is the primary driver (Anderson et al., 2002; Wehr \& Descy, 1998). Also, there are numerous types of phytoplankton associated with each water type (marine, brackish, and fresh). Dinoflagellates are most common in marine waters, diatoms are most common in brackish water, and cyanobacteria are most common in fresh water (Lopez, Dortch, et al., 2008; Lopez, Jewett, et al., 2008). For the purpose of this study, the focus will be cyanobacteria harmful algal blooms (cyanoHABs) since this research took place in fresh water environments.

One of the most common types of cyanoHABs are Microcystis spp., which has been found in 108 of 257 countries and territories in documented events across the globe (Harke et al., 2016). Microcystis spp. can be dangerous because they have the ability to emit toxins into their environment (Meissner et al., 2015; Watanabe \& Oishi, 1985). Microcystin is the most common type of toxin emitted by Microcystis spp., and its innate function is still under discussion (Meissner et al., 2015). Microcystin is a secondary metabolite produced by microcystis spp., and is classified as a hepatotoxin, which is a liver toxin (Meissner et al., 2015; Weber et al., 2020). Microcystin also has carcinogenic 
properties, with long-term exposure being linked to certain types of cancers; however, more research is needed on the subject (Meneely \& Elliott, 2013) One of its understood functions are that it serves as a defense mechanism against grazers and parasites. Additionally, there have been numerous studies that have illustrated a correlation between the presence of microcystin and an increased resistance and growth in conditions were there is oxidative stress and when there is inorganic carbon limitation (Meissner et al., 2015). The presence of microcystin can also stabilize the protein against protease degradation when there are high amounts of radiation (Meissner et al., 2015; Meneely \& Elliott, 2013). Some of these environmental conditionals are particularly conducive with projected impacts of climate change, which makes the production of microcystin a real concern.

Some documented cases of microcystin exposure have been concerning because of the adverse health effects on various species. For example, there have been documented cases where animals who ingested water contaminated with microcystin had livers that were engorged with blood and suffered fatal outcomes (Ingram \& Prescott, 1954; Watanabe \& Oishi, 1985). Humans have to ingest more toxins than animals to have this effect, however, chronic exposure can lead to long-term health effects or result in algal poisoning (Weber et al., 2020). The World Health Organization (WHO) set the safety standards for exposure to microcystins in drinking water and recreational exposure, which is $1 \mu \mathrm{l} / \mathrm{L}$ and $2 \mu \mathrm{l} / \mathrm{L}$, respectively (Meneely \& Elliott, 2013). Additionally, microcystin can bioaccumulate in various animals, including humans, primarily in the kidneys, intestines, lungs, and the carcass, but can also accumulate in the spleen and heart through long-term exposure (Meneely \& Elliott, 2013). If humans or other species were 
to ingest an animal with a high concentration of microcystin, it could have adverse effects on their health (Watanabe \& Oishi, 1985).

The actual function of microcystin is still not fully understood, however, their extracellular and intracellular roles are discussed in the literature (Meissner et al., 2015).

Microcystis spp. have been observed throughout the year when conditions are suitable, but are primarily present from July to October (Carmichael, 2008; Wehr \& Thorp, 1997). Previous studies (Watanabe \& Oishi, 1985; Wehr \& Thorp, 1997) have observed higher concentrations of microcystin during a cyanoHAB from the middle of July through August, with toxin concentrations declining through October. There are numerous drivers for the proliferation of Microcystis spp., which are conducive with the weather and general freshwater habitat conditions present from late summer through the middle of fall. Some of the primary drivers for the production of Microcystis spp. are high light availability, warmer temperatures, low turbidity, low flow periods, and high nutrient loading (Paerl \& Otten, 2016).

Many of these conditions are favorable for numerous types of HABs, however, Microcystis spp., especially, possess numerous traits and flexible genes that make them extremely competitive in comparison to other phytoplankton species. For example, Microcystis spp. are larger in size with gas vesicles that aid in their movement up the water column, which allows them to have prolonged light exposure, which aids their rapid proliferation (Meissner et al., 2015). Additionally, Microcystis spp. are able to form in oxygen depleted waters, unlike other algal species, giving them a competitive advantage and allows them to propagate further (Paerl \& Otten, 2016). In addition to these traits, Microcystis spp. have a high tolerance for high temperatures, are able to 
sequester dissolved inorganic and organic nitrogen, and have higher photosynthetic rates in high light exposure (Meissner et al., 2015; Paerl \& Otten, 2016). One of Microcystis spp. more problematic traits is that higher light availability has shown to be more correlated with the toxic strain of microcystin (Wells et al., 2015).

The proliferation and toxicity of Microcystis spp. can have far reaching consequences that can have a ripple effect on surrounding water systems. Some of these consequences include creating hypoxic conditions, large fish die offs (wild and farmed), illness or death of aquatic species, household pets, or mammals (including humans) who have consumed contaminated water or aquatic species, high water purification costs, inhibition of recreational activities, and alteration of ecosystems, to name a few. (Anderson et al., 2002; Codd et al., 2005). HABs are a serious concern since they threaten one of the most vital resources utilized by almost every living creature across the globe. If there are not significant changes to how water systems are manipulated, exploited, and managed, it is likely HABs will continue to increase in frequency and duration in coming years. Since HABs have a significant impact on the environment, economy, and social equity, it is crucial to understand why HABs are unsustainable and why it is crucial to improve the sustainability of impacted aquatic ecosystems. ii. Sustainability

All types of HABs can have a significant impact on the sustainability of a water system, however, the focus of this analysis will be on the consequences of cyanoHABs, specifically, in freshwater systems. CyanoHABs can be dangerous because of the toxins they release and how they drastically alter and impact an aquatic ecosystem, however, these are not the full extent of their impacts. Waterbodies are highly utilized by numerous 
actors for shelter, profit, or resources, which are critical for various species and systems. For this reason, it is crucial to break down how cyanoHABs impact on the environment, economy, and social equity (i.e. the three pillars of sustainability) to grasp the significance of this research. In its simplest form, sustainability is defined as living in a way that will not significantly impact future generations (Vos, 2007). The basic model of sustainability is to find a way to balance the positive and negative outcomes impacting the environment, economy, and social equity (Opp \& Saunders, 2013). CyanoHABs have a significant impact on each of these pillars, and currently, there are no widespread, successful management practices to maintain a sustainable water system. To improve the condition of waterbodies victim to cyanoHABs, it is pertinent to better understand how the current situation is unsustainable and significantly impacting each sector.

\section{Environment}

The formation and presence of cyanoHABs in freshwater systems have negative consequences on the environment and the species supported by the affected environment. As mentioned before, cyanoHABs impact the environment by creating eutrophic conditions, and accelerating this process that naturally takes hundreds or thousands of years (Anderson et al., 2002). Eutrophication generally occurs when bodies of water are loaded with nutrients, which are then used by algae to proliferate. Then the algae form dense mats, and depletes the oxygen in the water system, causing large die-offs of fish and other species (Gilbert \& Burford, 2017). Eutrophication and the production of cyanoHABs across the globe have been highly correlated with poor water quality, which is primarily caused by anthropogenic sources (Carmichael, 2008). Nutrient and other pollutant inputs can come from sewage, animal wastes, atmospheric deposition, 
groundwater inflow, and waste water and runoff from agricultural or urban sources which are overloading water systems (Anderson et al., 2002; Carmichael, 2008).

CyanoHABs thrive in these disturbed areas, unlike other aquatic species which cannot survive in these polluted environments. The biodiversity in freshwater systems continues to be threatened by numerous factors, including increased pollutants from agricultural and urban areas, drastic alterations in the environment, overexploitation of species and water resources, and many other factors (Collen et al., 2014). Conversely, invasive species and other nuisance species, like Microcystis spp., thrive in these disturbed areas and further decline biodiversity in aquatic ecosystems (Gilbert \& Burford, 2017). When a cyanoHAB is present, its toxicity can poison other species in that environment, or bioaccumlate in various species and cause even more impediments. As mentioned earlier, if humans or other animals ingest these contaminated species, the adverse health impacts can be compounded. This perfectly illustrates the extensive impacts cyanoHABs can have beyond their environmental consequences.

\section{Economy}

Humans also utilize these threatened water sources, and have economically suffered from some of the consequences of cyanoHABs. Over the years, cyanoHABs have continued to significantly impact numerous economies overlapping or associated with the aquatic systems. For example, fisheries in rivers, lakes, and coastal waters have become contaminated from HABs in the past, and have even resulted in large fish die-offs because of eutrophic conditions (Anderson et al., 2002). In Alaska, the shellfisheries have taken a significant financial loss exclusively caused by cyanoHABs. These fisheries generate 50 million dollars annually, and if there is a cyanoHAB present, they risk losing 
all of their revenue because of the contamination of their product (Sellner et al., 2003). CyanoHABs can also impact animals that do not live in aquatic systems, like livestock, horses, or pets. If these animals were to drink from a contaminated water source, it could have fatal and monetary costs (Gorham et al., 2017).

Additionally, there are numerous industries throughout freshwater systems that rely on the recreational use of the river to survive. There are many small businesses that generate their revenue from recreational activities in fresh bodies of water, such as kayaking, boating, swimming, etc. Without potable water, these industries lose their business and have the potential to fail if water quality continues to decline and if cyanoHABs increase in frequency and or duration (Clark et al., 2017). Just one bloom in an Ohio Lake cost local businesses approximately 37 to 47 million dollars in local tourism revenue over a period of two years. Small marinas are another example of an industry that is impacted by HABs. For example, in the U.S., small marinas support a multibillion-dollar recreation industry along river systems that is at risk if water quality and cyanoHABs continue to worsen (Ford et al., 2020). There is also the issue of cyanoHABs contaminating a drinking water source, and the costs associated with treating contaminated water and implementing management systems. Two notable cases of toxin cyanoHABs contaminating drinking water was in Lake Taihu in China and Lake Erie in the US. The contamination of these water sources led to a drinking water crisis in two major cities, and removing the cyanobacteria, along with the toxins, generated high water treatment costs (Burford et al., 2020).

In the U.S., treatment facilities are having to adapt to the occurrence and increased frequency of HABs. The EPA has been working with treatment plants surrounding Lake 
Erie, which were built before World War II, to find cost effective and successful solutions to treating water contaminated by a HAB (EPA, 2020). Sometimes these solutions involve adding more chemicals or updating the current technology at the treating plant, which could cost millions of dollars. In one study conducted in a lake in Ohio contaminated by a HAB, had documents that showed that more than 13 million dollars was spent in a period of two years just to treat the drinking water from the lake (EPA, 2015). Currently, the total economic costs of HABs in the US have been estimated to be approximately 2.2 billion dollars annually, which includes the effects on recreational use, property values, fishing, water treatment costs, etc. (Burford et al., 2020). These costs will continue to increase if better management practices, water quality, and, ultimately, the frequency of cyanoHABs do not improve.

\section{Social Equity}

In addition to the consequences cyanoHABs have on the environment and economy, people have been significantly impacted by the growing phenomenon. As mentioned previously, there can be significant economic costs of cyanoHABs that can have a substantial impact on many people, including their businesses. There is also the issue of human health when discussing the consequences of cyanoHABs. There are numerous routes of human exposure to cyanoHABs that include drinking contaminated water, ingesting contaminated seafood or plants, inhalation, and dermal exposure (Anderson et al., 2002; Meneely \& Elliott, 2013; Sellner et al., 2003). Through recreational exposure, especially, humans risk eye irritation, respiratory distress, dermatitis, and potential algal poisoning (Weber et al., 2020). These impacts can intensify through long-term exposure, and some studies (Meneely \& Elliott, 2013) have shown microcystin having carcinogenic 
properties that have been correlated to certain types of cancer. This is especially of concern to those who live near and frequently interact with these contaminated bodies of water. The negative impacts cyanoHABs can have on human health makes HAB control and management a dire concern for the future.

iii. Purpose and Hypothesis

All the previous examples are crucial drivers for the research conducted in this study. CyanoHABs are detrimental to the sustainability of water systems, and continue to intensify as these blooms become more frequent and last longer. This phenomenon demands more attention and research aimed at understanding these blooms, and potentially finding new solutions for these problems. Despite the numerous studies performed and papers written about cyanoHABs, gaps in the literature remain present. These include an understanding of the frequency, extent, and duration of cyanoHABs (Wells et al., 2015). The purpose of this research is to build on previous literature about HABs in large river systems by looking at toxin concentrations in different habitats along the Ohio River throughout the duration of a cyanoHAB. These different habitats include bays, creeks, the river, and the main channel of the Ohio River. Since these systems are connected, this research is interested in discovering where HABs are forming first and where and when they have the highest and lowest concentrations of toxins, if present. Research Hypotheses

1. Hypothesis 1: I predict these blooms are forming more rapidly in bay habitats and then enhancing algal communities in the river, to form larger blooms. Bays, especially marinas, are generally more polluted and have lower turbidity than the 
main channel, resulting in more light exposure. These conditions are ideal for the formation of a cyanoHAB.

2. Hypothesis 2: I predict creek habitats will have the lowest toxin concentration throughout the study because of the water is fast-moving, in comparison to the other study habitats, and feeding pollutants directly into the river. Thus, increasing the nutrients levels in the river.

3. Hypothesis 3: I predict the main channel of the river will have lower toxin concentrations than bay habitats, but higher toxin concentrations than creek habitats. The creeks and bays feeding into the Ohio River carry a variety of pollutants from agricultural and urban runoff, which can provide a conducive environment for the cyanoHAB.

4. Hypothesis 4: I predict the toxin concentrations will be higher earlier in the in the bloom in comparison to the end of the bloom. Previous research (Carmichael, 2008; Wehr \& Thorp, 1997) has illustrated this trend, and I predict these findings will remain consistent in this study.

These events have been increasing in frequency over the past few decades, however, it is possible historical HAB events were not detected or recorded for a myriad of reasons (Anderson et al., 2002). Historically, HABs have been documented more in lakes and coastal waters, however, more blooms have been appearing in other freshwater systems, such as river, bay, and creek habitats (Wehr \& Descy, 1998). Lake ecosystems, including their phytoplankton communities, are better understood and researched than large river ecosystems. Despite the increased frequency of HABs in river systems, there are not 
sufficient monitoring systems or clear understanding of the dynamics of the bloom (Anderson et al., 2002). Studying HABs in large river systems brings with it new challenges because blooms in riverine systems are driven by different factors than in lake and marine systems (Wehr \& Thorp, 1997). This study attempts to enhance the knowledge of cyanoHABs in large river systems and their surrounding ecosystems to provide more information to improve management and monitoring systems. 


\section{CHAPTER II: MATERIALS AND METHODS}

\section{i. Study Site}

This research was conducted in the McAlpine Pool in the Ohio River. The Ohio River is formed from the confluence of the Monongahela and Allegheny Rivers in Pittsburg, Pennsylvania. The Ohio River runs 981-miles from Pittsburg to Cairo, Illinois where it joins the Mississippi River (Stefanavage, 2010). There is a long history of canalization and dam construction in the Ohio River to improve navigation throughout the river and increase connectivity to other river systems. Constructing the navigation system in the Ohio River included the addition of 20 locks and dams with a standard nine foot depth along the entirety of the river (Newman, 1979). The modifications transformed the Ohio River into a central place of commerce on the river and in the cities the river passes through. These changes also impacted the ecosystem of the river by drastically altering the landscape and the species composition in the river. Before there were some environmental regulations implemented in the $1980 \mathrm{~s}$, unregulated activities, such as point-source pollution, were detrimental to the species utilizing the Ohio River. Before the 1980 s, a study indicated $90 \%$ of samples along the Ohio River were classified as biologically impaired, compared to today, where only $34 \%$ of samples are considered biologically impaired (Miltner, 2018). Of the 34\%, approximately one third of these sample sites are impaired because of eutrophic conditions, which is primarily 
attributed to extreme nutrient enrichment and the development of HABs. The concentration of nutrients are even higher during low-flow periods when the river mimics the conditions of a lake (Miltner, 2018).

Previously a free-flowing river, the Ohio River is now a series of impoundments which changes the river dynamics, fish community, and the occurrence of HABs (Stefanavage, 2010). One of these impoundments is the McAlpine Pool, which is located in the section of the Ohio River that runs by Louisville, Kentucky. The McAlpine Pool is 75.1 miles long, and is located between the Markland (river mile 531.7) and McAlpine (river mile 606.8) Locks and Dams (Stefanavage, 2010). These alterations to the Ohio River has created suitable habitats for cyanoHABs to flourish in this environment. Over the past century, there have been approximately five cyanoHABs documented in the Ohio River, however, it is predicted there were more undocumented blooms throughout this period. One of the first blooms on record in the Ohio River was in West Virginia in 1930, which is believed to have been brought on by an extended drought period throughout the Ohio River Basin (Tisdale, 1931). Another bloom was recorded and studied thoroughly was in 1991-1992 in the Ohio River (Wehr \& Thorp, 1997). Although there was another bloom recorded in 2007, the most significant $\mathrm{HAB}$ on record occurred in 2015, and stretched approximately 650 miles, almost the entirety of the Ohio River (ORSANCO, 2021). This bloom was present in from August to October and received significant media coverage, which amplified the general public's concern about HABs.

In late summer of 2019, a cyanoHAB started to form in McAlpine Pool and other parts of the Ohio River. This bloom was approximately 200 to 300 miles in length throughout the Ohio River, however, it is possible that it was more extensive because of 
limited monitoring systems. Throughout the month of September 2019, Louisville had a significant drought period, which aided the McAlpine Pool to resemble a lake. The lack of rain caused there to be a lack of mixing, low turbidity, and very little water runoff (Weber et al., 2020). This allowed for light to penetrate further into the water column, allowing for algal colonies to rapidly proliferate and form a bloom until the middle of October in 2019. The bloom diminished after there was a large rain event mid-October, which allowed for enough mixing to dissipate the bloom.

Within the McAlpine Pool, three sites (bay, creek, and river) were sampled almost daily from the middle of August until the middle of October (Figure 1). There were three additional sites were sampled periodically throughout the bloom, but not daily (Figure 1). Additionally, there were two sampling days, one in September and one in October, that were taken from a boat (Figure 2). The boat allowed access to various habitats throughout 
the channel of the river that would be impossible to reach from land. These habitats were classified as above island, below island, main channel, side arm, and bay habitats.

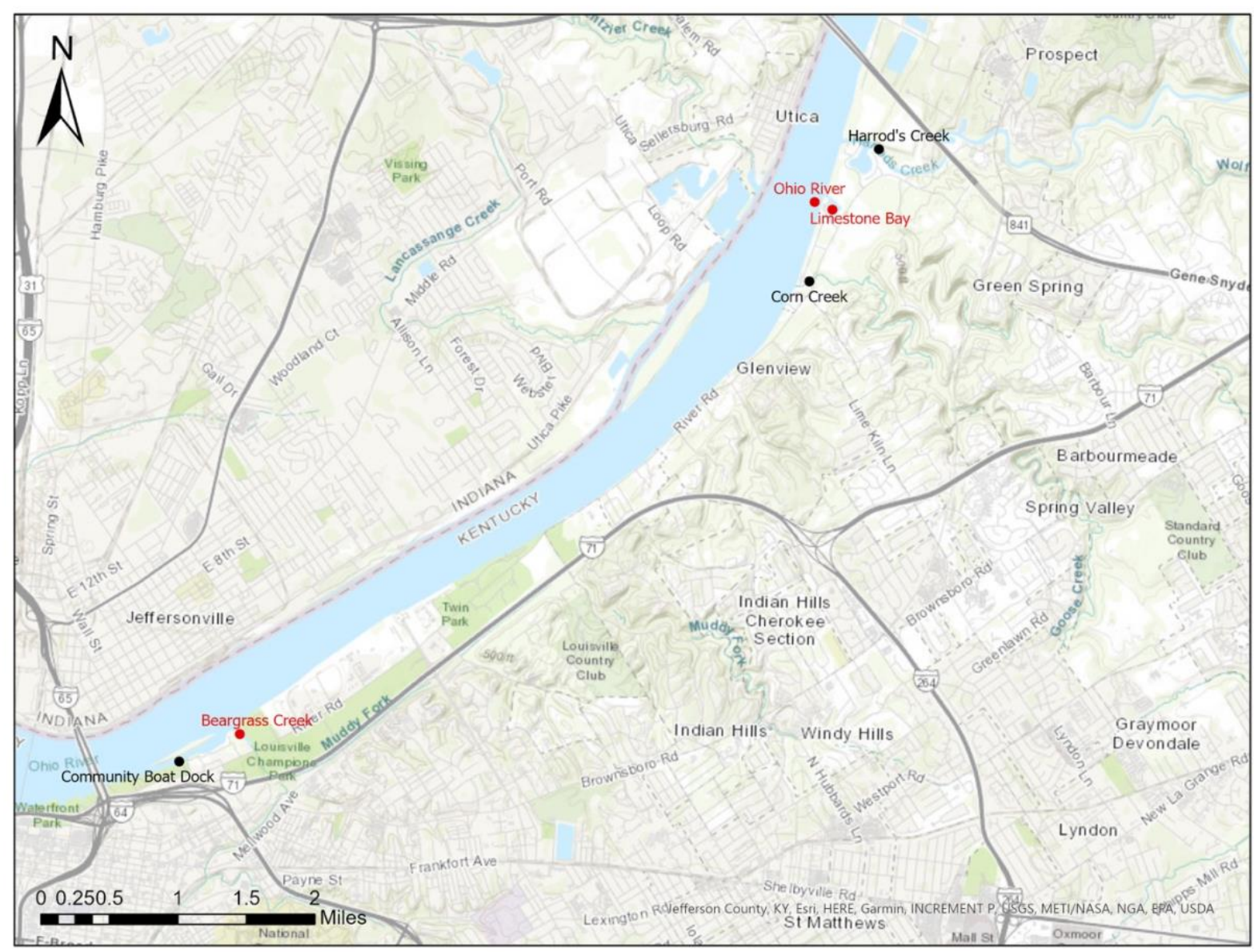

Figure 1. Sampling sites in the McAlpine Pool in the Ohio River. Red sampling sites were sampled almost daily, and the black sampling sites were sampled periodically throughout the study. 


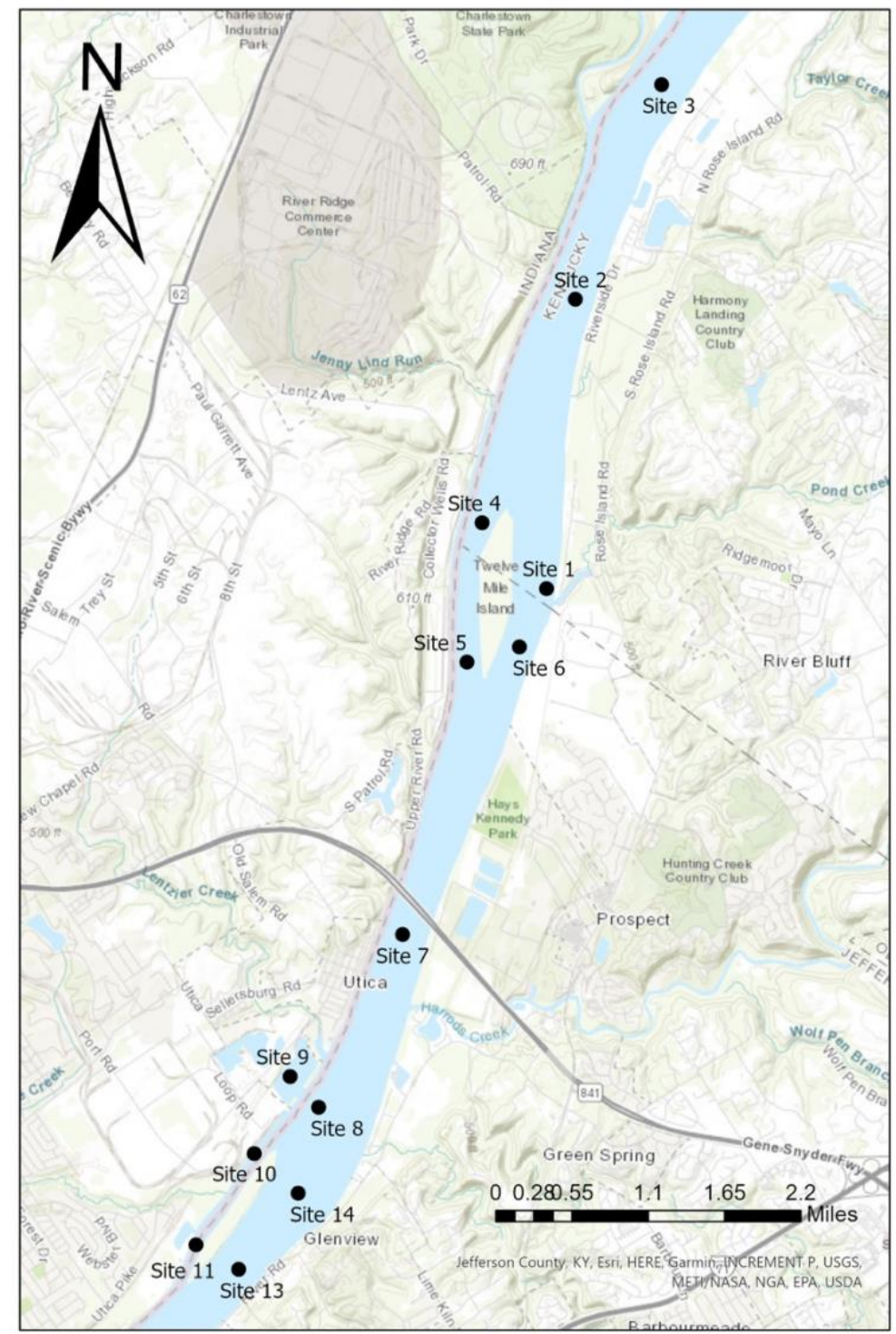

Figure 2. Sampling sites from the two boat sampling days that took place September 25th and October 9th. ii. Methods

Sampling began in mid-August and continued through the beginning of October in Louisville, KY in 2019. Samples were collected almost daily, or as supplies and weather permitted, in $500 \mathrm{~mL}$ plastic bottles. These samples were gathered from three different habitats in the McApline Pool in the Ohio River (bay, creek, and river). 
Specifically, samples were collected daily from Limestone Bay, the Ohio River, and the mouth of Beargrass creek (Figure 1). Other sites included Harrod's Creek, Corn Creek, and the Ohio River from the community boat dock (Figure 1). Most of these sites were chosen because of their feasibility for the study, including meeting site needs and having unlimited access to each site. Samples were collected from the shore of these waterbodies at convenient access points to the surface water. With the help of docks, bay habitat samples were able to be collected further out beyond the shore. Each bottle was filled with surface water in each habitat and was immediately stored in a freezer until it was ready for analysis. In addition to near-daily sampling, there were two days samples were collected on a boat to reach different habitats throughout the main channel of the river (Figure 2). The first sampling day took place on September 25th and the second was on October 9th, when the HAB was visible in thick patches in the Ohio River. Samples were collected from the side of the boat after the boat had been turned off for approximately two minutes. Air temperature, weather, and the date were also recorded as additional variables throughout the entire study.

Next, ELISA tests were used to measure the toxin concentration, if present, in each sample. Each sample was replicated twice for the ELISA tests, which resulted in 118 replicates (59 samples) from the continuous sampling days and 62 replicates (31 samples) from the boat sampling days. Microcystins-ADDA ELISA tests were used from Abraxis to measure the concentration of microcystin by detecting microcystins, nodularins, and their congeners by their particular antibodies. First, the cells needed to be lysed, which required two freeze thaw cycles. When the samples were ready for the ELISA tests, two replicates of each sample were tested in a microliter plate. The ELISA 
tests involved a four-step process to measure the absorbance for each replicate. First, an antibody solution was added to each individual well, and then washed with a buffer solution after 90 minutes. Second, an enzyme conjugate was added to each well, and washed with a buffer solution after 30 minutes. Third, a substrate solution was added to each well for 30 minutes, and then a stop solution was added to each well. Lastly, the microplate is put into a photometer to read the absorbance of each well. Once the absorbance for each sample was recorded, the values needed to be converted to toxin concentration. This involved calculating the $\% \mathrm{~B} / \mathrm{B} 0$ for each standard, plotting the values on a standard curve, and using the equation from that curve to calculate the concentration for each sample. The detection limit of the ELISA tests was any sample below 0.15 or any sample above $5 \mu \mathrm{l} / \mathrm{L}$.

Once the toxin concentration was calculated, I ran a generalized linear mixedeffects model on each dataset (continuous sampling days and boat sampling days) within R-studio. To analyze the data from each sampling day, the data was log transformed to make it fit normality assumptions. The original data was transformed because it appeared to be right skewed. Then a linear mixed-effects model was made in R-Studio with the response variable (log concentration), the fixed effects (site type, temperature, wind), and the random effects (date and site). An ANOVA was used on the model to find the pvalues for the fixed effects. To analyze the data from the two boat sampling days, the data was, again, right skewed and needed to be log transformed to make it fit normality assumptions. Then a linear mixed-effects model was made in R-Studio with the response variable (log concentration), the fixed effects (site type and month), and the random effects (date and site). An ANOVA was run on the model to find the p-values for the 
fixed effects. Excel was also used to calculate microcystin concentrations from each dataset (continuous sampling days and boat sampling days). 


\section{CHAPTER III: RESULTS}

\section{i. Continuous Sampling Days}

Overall, toxin concentrations were the lowest in August and the beginning of September, and peaked at the end of September and decreased again in the beginning of October (Figure 3 and Figure 4). The overall highest toxin concentration was recorded on September 24th at $4.398 \mu \mathrm{l} / \mathrm{L}$ (Figure 5). The highest average toxin concentrations for bay and creek habitats were recorded on September 24 th at $4.392 \mu 1 / \mathrm{L}$ and $2.016 \mu 1 / \mathrm{L}$, respectively, and the highest average toxin concentration for river habitats was recorded on September 27 th at $1.368 \mu \mathrm{l} / \mathrm{L}$ (Figure 3). The highest average toxin concentration for each habitat (creek, bay, river) was recorded in the last week of September (22-28) (Figure 4). The overall lowest toxin concentration was recorded on August 17 th at 0.038 $\mu 1 / L$ (Figure 6). The lowest average toxin concentration for bay habitats was on August 10 th at $0.0816 \mu \mathrm{l} / \mathrm{L}$, creek habitats was on September 12 th at $0.0493 \mu \mathrm{l} / \mathrm{L}$, and river habitats was on September 20th at $0.00436 \mu 1 / L$ (Figure 3). 
Average Toxin Concentrations Over Time in Each Habitat

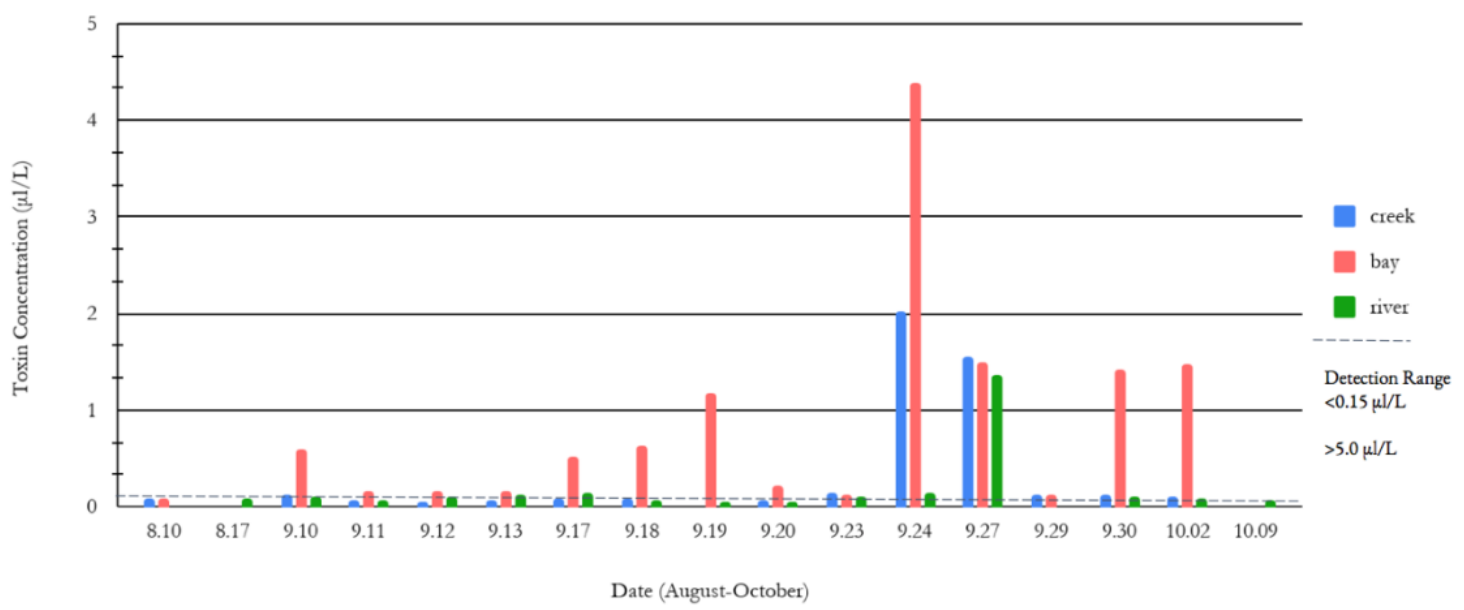

Figure 3: Average toxin concentrations in each habitat for each day of sampling.

\section{Average Toxin Concentration Per Week (August-October)}

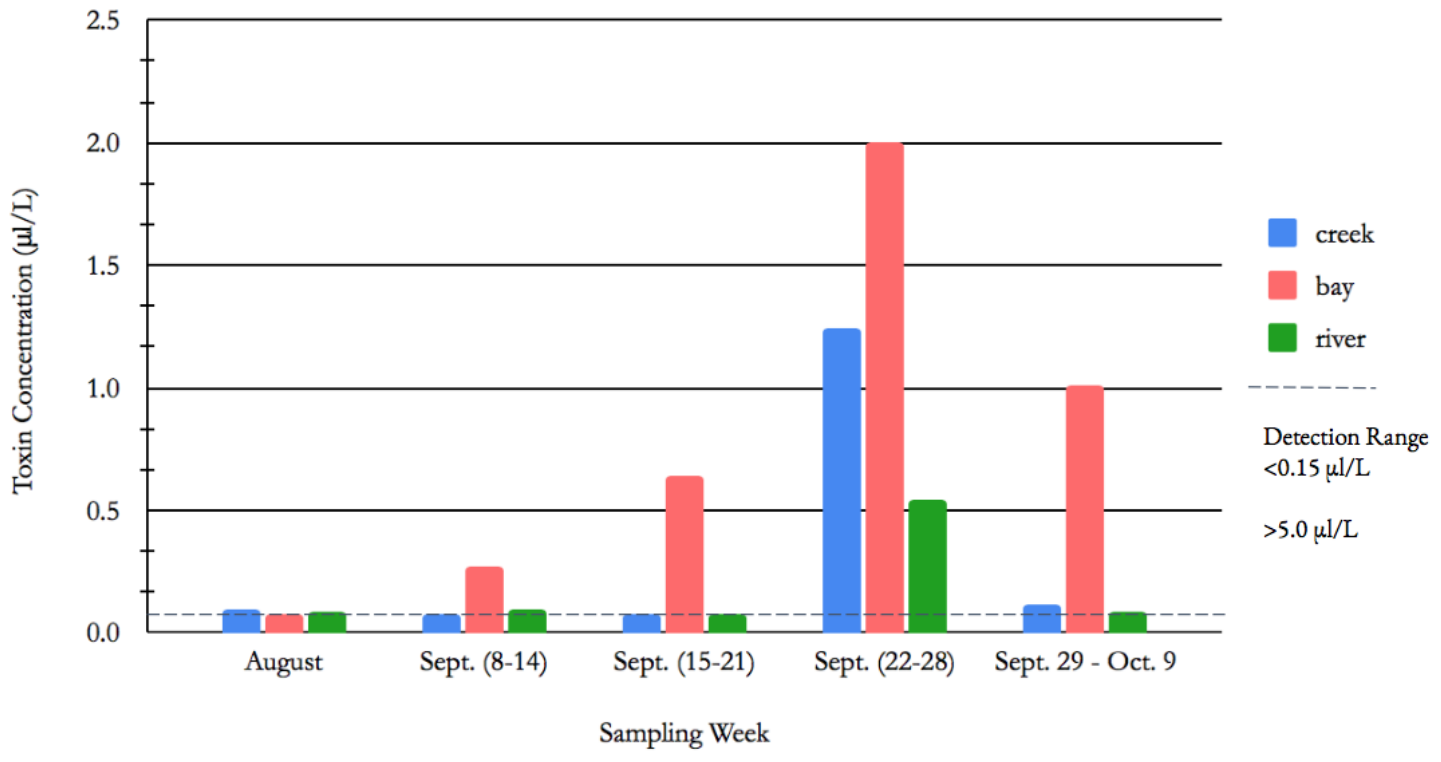

Figure 4: Average toxin concentrations in each habitat for each week of sampling. 
Toxin Concentration vs. Sampling Date (Max.)

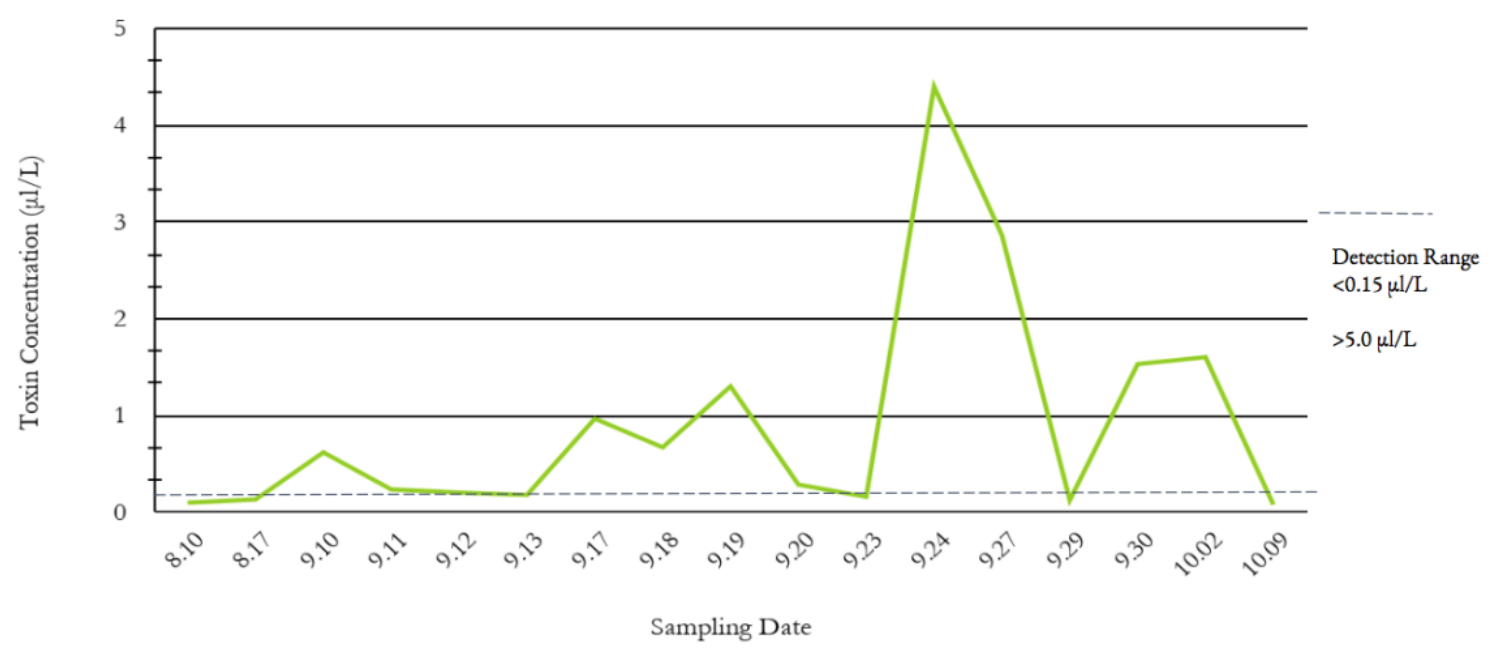

Figure 5: Maximum toxin concentrations for each recorded sampling day.

Toxin Concentration vs. Sampling Date (Min.)

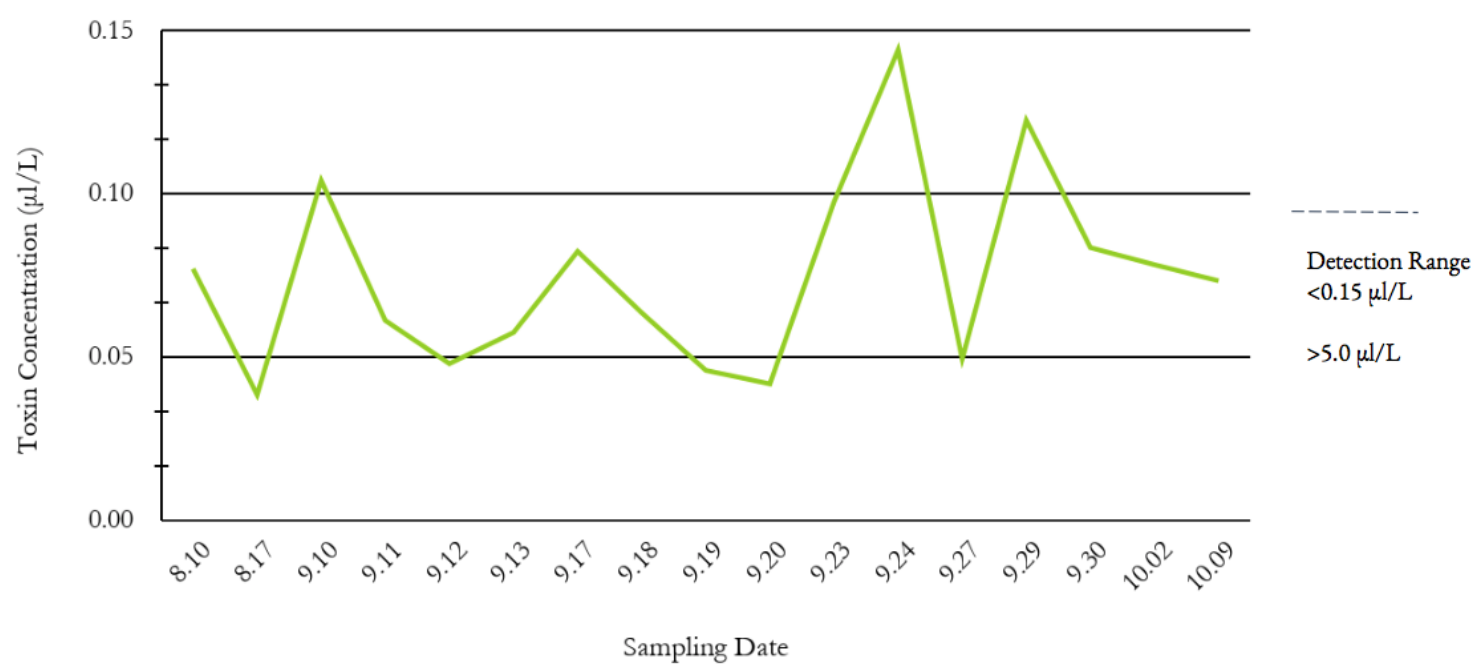

Figure 6: Minimum toxin concentrations for each recorded sampling day.

It is also crucial to look at any samples that exceeded the World Health Organization's (WHO) established safe limit for microcystin exposure for humans in terms of recreational exposure. The only sampling days that had toxin concentrations higher than the recreational safe limit set by the WHO $(2 \mu 1 / L)$ was September 24th and 
September 27th (Figure 5). On September 24th, toxin concentrations above the WHO safe limit were found in samples from bay habitats $(4.392 \mu \mathrm{l} / \mathrm{L})$ and creek habitats $(2.016$ $\mu 1 / \mathrm{L}$ ) (Figure 5). On September 27th, toxin concentrations above the WHO safe limit were found in samples from bay habitats $(2.558 \mu \mathrm{l} / \mathrm{L})$ and river habitats $(2.688 \mu 1 / \mathrm{L})$ (Figure 5). The average toxin concentration of every other sampling day fell below $1 \mu \mathrm{l} / \mathrm{L}$ (Figure 7).

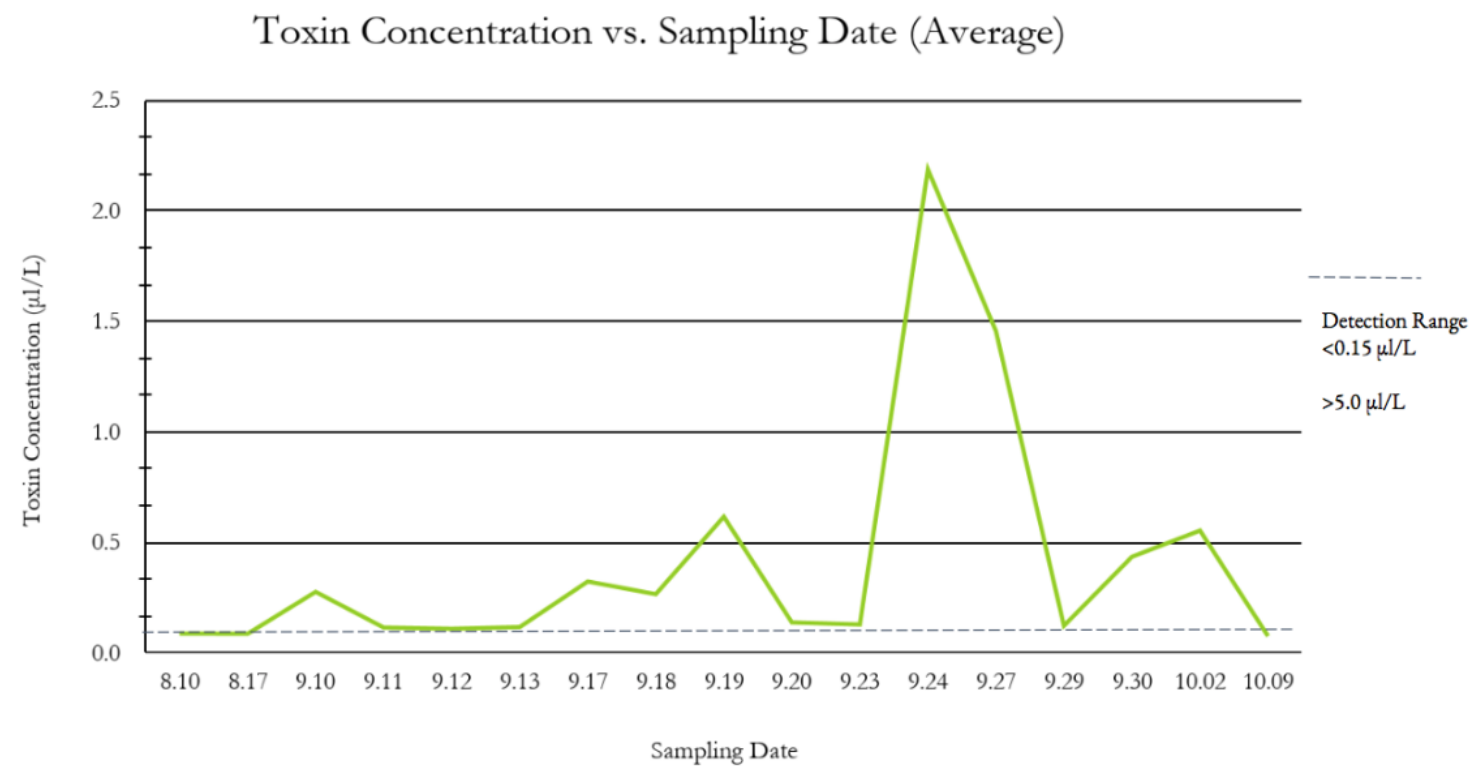

Figure 7: Average toxin concentrations recorded for each sampling day.

As mentioned earlier, a generalized linear mixed-effects model in R-Studio was run with the response variable (log concentration), the fixed effects (site type, temperature, wind), and the random effects (date and site). An ANOVA was used on the model to find the p-values for the fixed effects. None of the fixed effects had significant p-values, however, site type is trending with a p-value of 0.097 , since it is below 0.10 and above 0.05 (Table 1). Creek and river habitats appear to have similar results, whereas, bay 
habitats show higher toxin concentrations in comparison to creek and river habitats (Figure 8). To further analyze the significance of site type, T-Tests were run between each site type, using a Bonferroni correction (p-value of 0.0167). After using the Bonferroni correction, the differences between bay sites and river and creek sites were significantly different (Table 2). There was no significant difference between creek and river habitats (Table 2). There were a substantial number of outliers in the dataset of creek and river site types, which could possibly explain the trending p-value (Figure 8).

\begin{tabular}{c|c} 
Fixed Effects & P-Value \\
\hline Wind (mph) & 0.685 \\
Site Type & 0.097 \\
Temperature & 0.969
\end{tabular}

Table 1: P-values of fixed effects from linear fixed-effects model. 


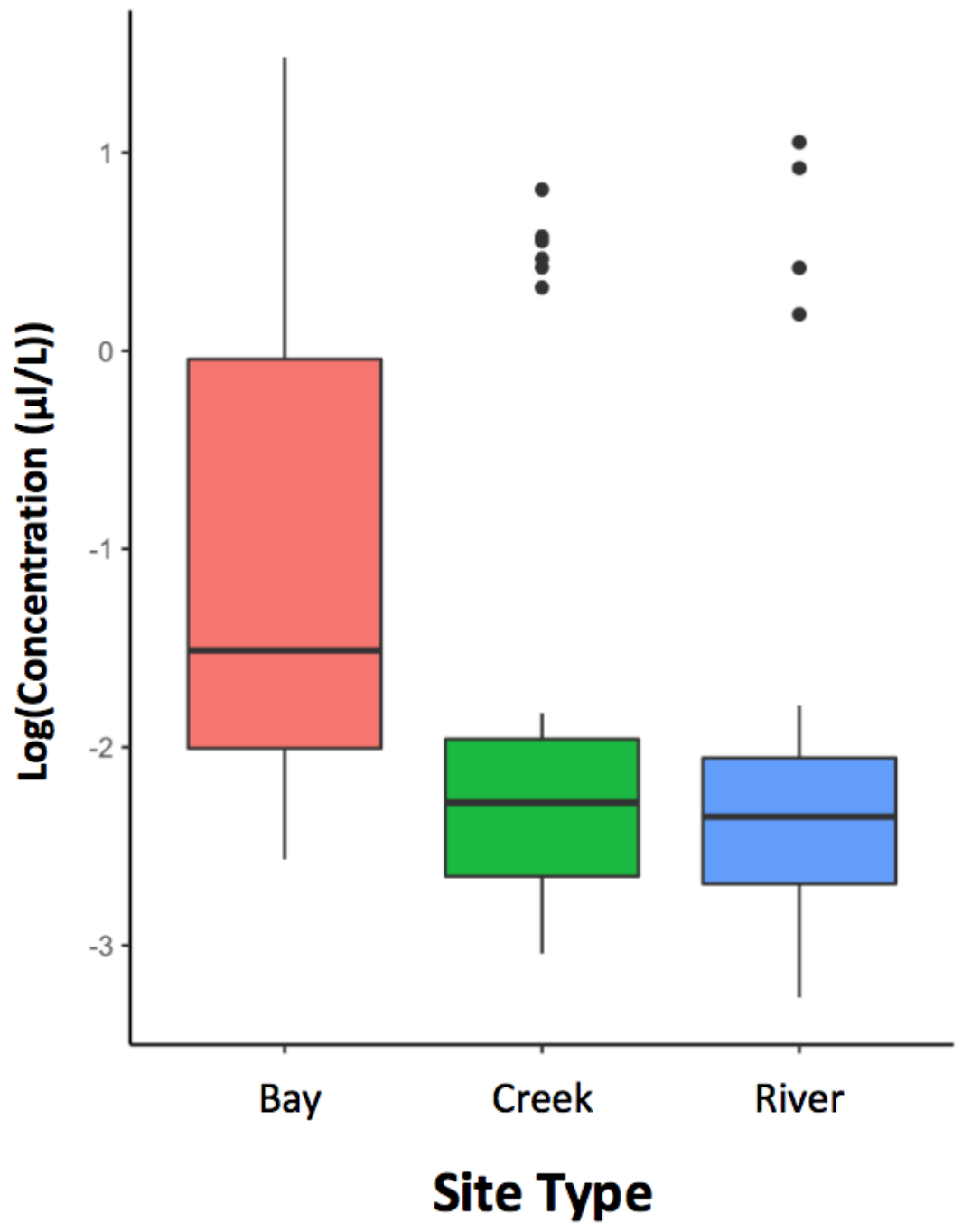

Figure 8: Box plot for toxin concentrations for each habitat for continuous sampling day.

\begin{tabular}{c|c} 
T-Test & P-Value \\
\hline Bay vs. Creek & 0.00718 \\
River vs. Bay & 0.00000292 \\
Creek vs. River & 0.176
\end{tabular}

Table 2: T-Test results from direct habitat comparisons. 


\section{ii. Boat Sampling Days}

To analyze the data from the two boat sampling days, a linear mixed-effects model was made in R-Studio with the response variable (log concentration), the fixed effects (site type and month), and the random effects (date and site) (Figure 9). An ANOVA was run on the model to find the p-values for the fixed effects. There was no significant difference between site type, however, the difference between months was highly significant (Table 3 and Figure 9). The average toxin concentration for the sampling day in September was $0.1408 \mu \mathrm{l} / \mathrm{L}$ and the average toxin concentration for the sampling day in October was $8.011 \mu \mathrm{l} / \mathrm{L}$. In September, the toxin concentrations recorded did not exceed $0.201 \mu \mathrm{l} / \mathrm{L}$, and did not fall below $0.0904 \mu \mathrm{l} / \mathrm{L}$ (Figure 10). In October, the toxin concentrations recorded did not exceed $11.279 \mu \mathrm{l} / \mathrm{L}$, and did fall below $2.669 \mu \mathrm{l} / \mathrm{L}$

(Figure 10). In September, the habitat with the highest average toxin concentration was in below island habitats $(0.2027 \mu \mathrm{l} / \mathrm{L})$, and the lowest average toxin concentration was in bay habitats $(0.2027 \mu \mathrm{l} / \mathrm{L})$ (Figure 11). In October, the habitat with the highest average toxin concentration was in above island habitats $(10.4354 \mu \mathrm{l} / \mathrm{L})$, and the lowest average toxin concentration was in main channel habitats $(7.4737 \mu 1 / L)$ (Figure 11). However, as mentioned before, there was not significant difference between habitats for the two boat sampling days (Table 3 ). 


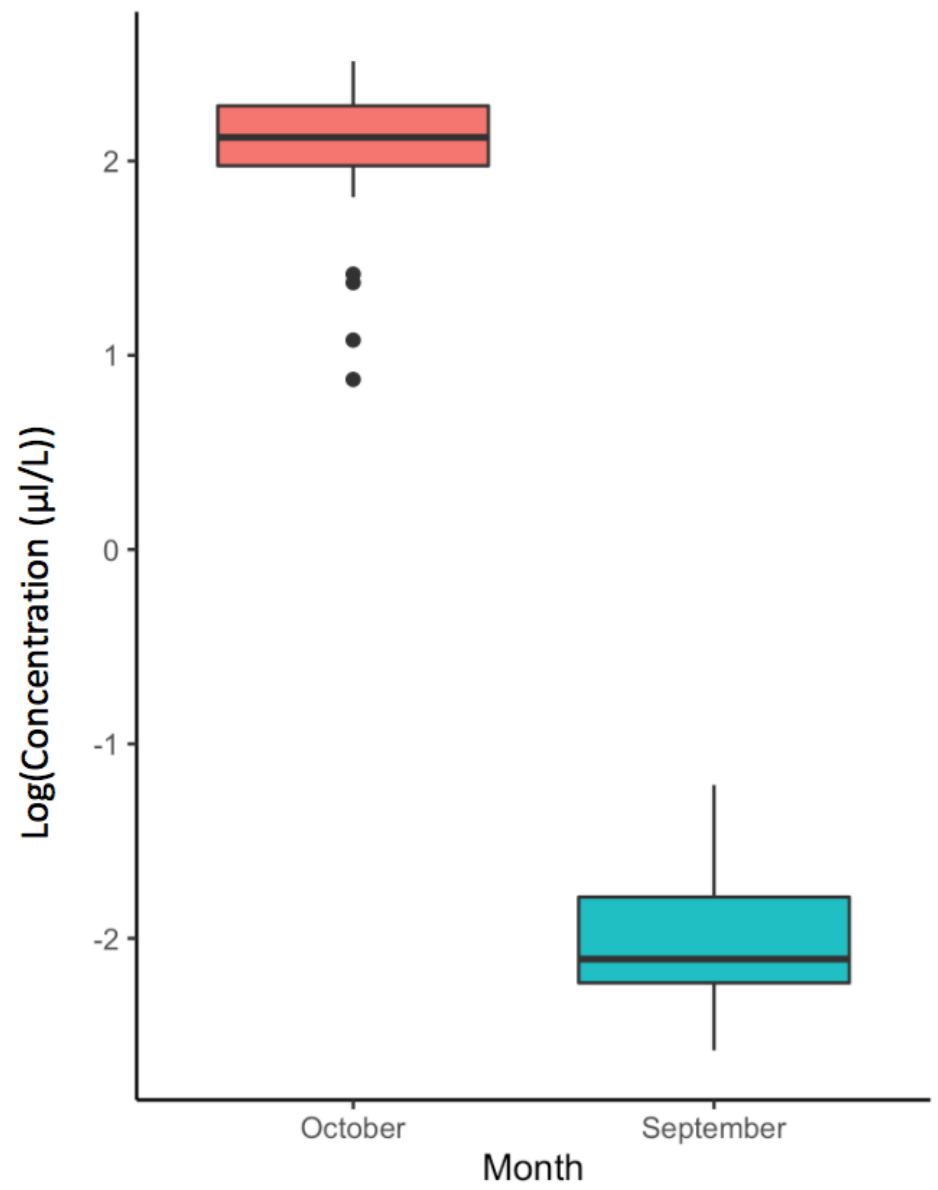

Figure 9: Box plot for toxin concentrations for each boat sampling day between each month.

Fixed Effects

Site Type

Month
P-Value

0.99

$<2 \times 10^{\wedge}-16$

Table 3: P-values of fixed effects from linear fixed-effects model. 


\section{Average Toxin Concentrations at Each Site}

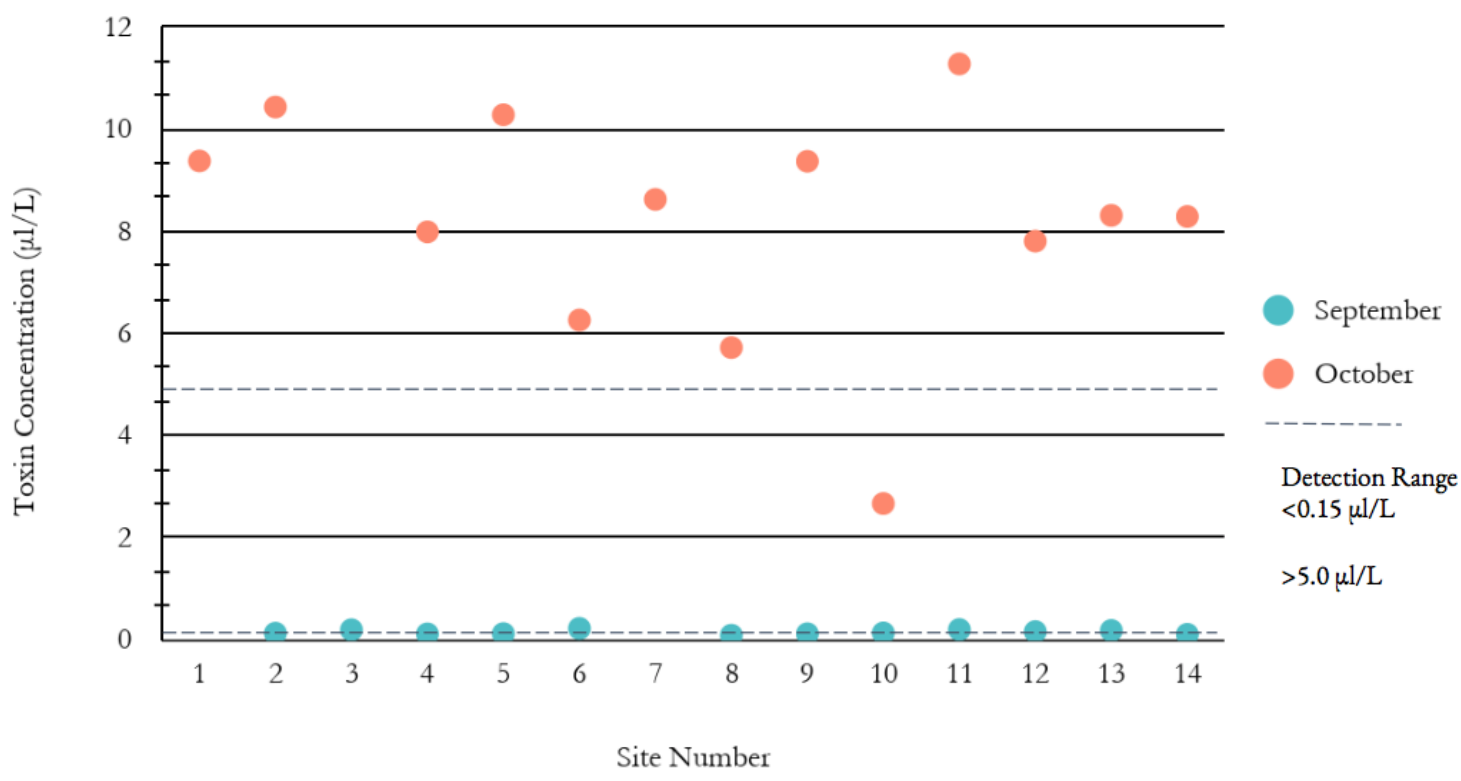

Figure 10: Average toxin concentrations for each site for the two different sampling days that took place in September and October.

\section{Average Toxin Concentration Difference Between Habitats and Months}

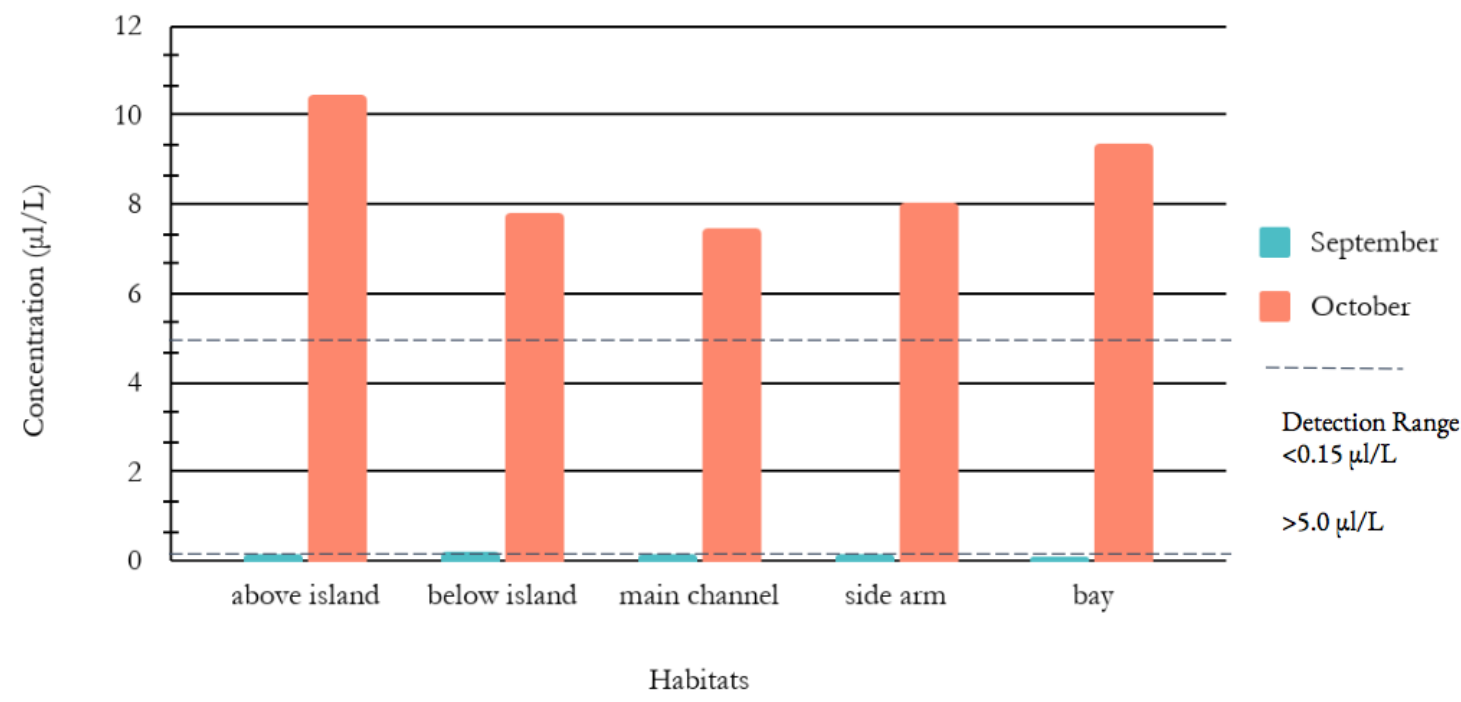

Figure 11: Average toxin concentrations for each habitat for the boat sampling days in September and October. 


\section{CHAPTER IV: DISCUSSION}

There were some results from the study that were expected, and some that were in stark contrast to previous studies conducted and the hypotheses for this study. First, bay habitats did have significantly higher toxin concentrations throughout the duration of the bloom in comparison to creek and river habitats; which provides supporting evidence for hypothesis 1 . Even though bay habitats consistently had higher concentrations than the other habitats sampled, there was not a consistent pattern of an increase or decrease in toxin concentration throughout the sampling period. There were unpredicted drops and spikes in the toxin concentration of bay samples throughout the study, even though the highest peak of toxin concentration occurred towards the end of September. These samples created numerous outliers, which prevented a clear pattern from emerging from the data. Some of these outliers could be better explain if there were more variables measured throughout the study, such as sampling from deeper in the water column, including more sites, measuring turbidity, velocity, water temperature, and other countless factors. It would be critical to include some of these, if not all, of these variables in future studies to potentially provide a better explanation for some of these outliers in the dataset.

Second, hypothesis 2 and 3 were not supported by the data collected in this study because the river samples were generally lower in toxin concentration than in creek 
samples. Despite this trend, there was not a significant difference between river and creek habitats from the samples that were collected. If there were more river and creek sites included in the continuous, daily sampling days, there could have been more data to understand the dynamics of these habitats studies in this research. Third, hypothesis 4 was also false because toxin concentrations were higher towards the beginning of the bloom, versus at the beginning of the bloom. Even though there were not many clear trends throughout the study, toxin concentrations were clearly impacted by the date. Based on the data collected, the lowest toxin concentrations at the beginning of the study, and there was an evident peak in toxin concentrations towards the end of September.

One of the most surprising results found in this study was the toxin concentrations being higher towards the end of the bloom versus at the beginning. Preceding research done in the Ohio River has documented previous cyanoHABs having higher toxin concentrations in July (or earlier in the bloom) than in October (later in the bloom) (Watanabe \& Oishi, 1985; Wehr \& Thorp, 1997). Watanabe \& Oishi (1985) found that toxicity in Lake Suwa in Nagano Prefecture was highest from the middle of July through August, and drastically fell (by 50\%) in late August and September. Additionally, a study by Wehr and Thorp (1997) illustrated higher toxin concentrations (more than double) of microcystin in the Ohio River in July than in October. The highest toxin concentration recorded in this study was on September 24th, whereas, the lowest toxin concentration was recorded on August 17th; which is the inverse of the finding from Watanabe \& Oishi (1985). It is challenging to pinpoint why there is a significant difference between the findings in this study versus previous studies, however, it would be informative to repeat 
this study in more habitats and pools along the Ohio River during a cyanoHAB to see if this pattern continues.

Another unexpected finding was that air temperature did not have a significant effect on bloom production. This differs from previous research which found high correlation between the temperature and the growth of the bloom and toxin concentration. Weber et al. (2020) found that air temperature significantly impacted bloom production, with higher temperatures significantly increasing algal growth. However, that particular study was done in a controlled lab setting, which may not directly translate into active aquatic ecosystems. Also, this result could potentially be contributed to the amount of samples or missing some sampling days during the bloom. It is possible that with more continuous sampling, or even multiple samplings throughout each day, there could be more data to find a stronger correlation between temperature and toxin concentration.

Even though it was predicted that bay habitats would have higher toxin concentrations than every other habitat sampled, this contrasts what has been found in previous studies. These findings contradict previous literature (Gorham, 1964), where toxin concentrations were higher in the main channel of the Ohio River versus lake habitats. Even though lake habitats were not sampled in this study, bay habitats to some extent resemble lake habitats because they are more stagnant than river or creek habitats. The only time the main channel of the Ohio River had significantly higher toxin concentrations was during the October boat sampling day. However, all of the toxin concentrations were higher than $5 \mu \mathrm{l} / \mathrm{L}$, which according to the ELISA test, required additional testing to obtain a more precise concentration. Since, samples were contaminated before these tests were redone, 
any toxin concentration above $5 \mu \mathrm{l} / \mathrm{L}$ must be reported as such, and cannot trust the accuracy of these values.

The boat sampling days are harder to explain because of the drastic differences in concentrations between the continuous sampling days. The first sampling day in September took place on the 25 th, which was only one day after the highest recorded toxin concentration from the continuous sampling days. However, this boat sampling day resulted in some of the lowest toxin concentrations from the entire study. Additionally, the second boat sampling day took place on October 9th, and had the highest toxin concentrations recorded from the entire study. The maximum toxin concentration on October 9th from the continuous sampling days was $0.0801 \mu \mathrm{l} / \mathrm{L}$, which was the lowest maximum concentration recorded from the entire study, regarding the continuous sampling days. Some possible errors could include the boat disturbing the water column, pushing surface algal colonies together or apart, or mixing the water underneath with the propeller could have all skewed the results from these sampling days. Regardless, the contrasts in data from the continuous sampling days and the boat sampling days illustrates the complexity of these blooms, and calls into question the other factors that could potentially be influencing the development and location of the bloom. The results from this study are limited in answering these questions because boat sampling was only available for two isolated days throughout the entirety of the three-month study. 


\section{CHAPTER V: CONCLUSION}

This study built on previous literature and findings, but, also, produced findings that were drastically different from previous studies. With more sampling days and more samples from each habitat, it might be possible to draw more accurate conclusions or stronger correlations from the data collected. However, the results from this study call into question many known characteristics of cyanoHABs that require further exploration. There is a desperate need for more research about HABs in large rivers. Currently, there is an average of 7 cyanoHABs days per waterbody per year, and some predictions show this number increasing to 18-39 cyanoHAB days by the year 2090 (Weber et al., 2020). If these predictions come to fruition, it is crucial to improve monitoring systems and networks along all bodies of water, including the Ohio River. Sections of the Ohio River, like the McAlpine Pool, are not isolated from one another, but instead are extremely connected. If there are nutrient loading sources upstream, they can be transported downstream and support the formation of a larger bloom (Anderson et al., 2002). For this reason, it is important to enhance the network of monitoring systems to improve water conditions and protect anyone utilizing the river during bloom.

In addition to city and state networks, the general public needs to be informed and involved about HABs in their environment. Foundational change to improve water quality requires support and interest beyond the scientists advocating for improved water 
systems. The general public needs to be more aware of how they could be directly impacted by the degradation of their environment to become more involved and supportive of mitigation strategies (Bauer et al., 2010). As mentioned in the introduction, cyanoHABs can have far reaching impacts that can and will impact numerous systems, including the environment, economy, and social equity. For these reasons, especially, it is important to extend monitoring networks to the general public, so people are aware and have stake in what is happening to their environment. To better engage the public in HAB management there needs to be a focus on socioeconomic impacts, recreational and drinking water impacts, public health impacts, risk communication, institutional coordination, and improved education and outreach (Bauer et al., 2010). People need to understand the dangers of a $\mathrm{HAB}$ and what factors are causing these blooms to occur, so they can demand and create change in how water resources are exploited and polluted today.

There needs to be better monitoring systems to improve detection of HABs and management systems. A potential monitoring system proposed by numerous authors is satellite remote sensing (Clark et al., 2017; Gorham et al., 2017; Urquhart et al., 2017). This method has had success in lake susceptible to HABs, however, large rivers pose different obstacles to successful satellite monitoring. For example, a study (Gorham et al., 2017) analyzing the efficiency and success of remote sensing in Ohio illustrated some of these benefits and challenges. Remote sensing was able to function as an early monitoring device to indicate the need for additional testing, however, only half of the waterbodies in Ohio were able to be monitored. This has some benefits, however, there is still a large portion of waterbodies susceptible to a bloom that are not being monitored 
(Gorham et al., 2017). River systems are far more extensive than lakes, and require additional monitoring strategies to be successful in monitoring and managing a bloom. With more public outreach, the surrounding communities of these bodies of water could also contribute to monitoring the formation of bloom. If a network was created to connect with multiple communities about how to identify and report a bloom, this could significantly expand the current monitoring network.

These actions and more research are extremely important for the future of aquatic systems across the globe. Climate change is a pressing matter that is already impacting numerous environments and ecosystems, and riverine systems are no exception. There are many researchers and studies that conclude climate change impacts will exacerbate HABs in numerous regions (Gorham et al., 2017; Wells et al., 2015). Rising temperatures alone could contribute to higher surface water temperatures and vertical stratification. Changes in participation patterns could also create ideal conditions for HABs and increase their frequency and duration in susceptible regions (Paerl \& Otten, 2013; Wells et al., 2015). Climate change effects will make it even more difficult to monitor and control HABs, which will only be exacerbated if more mitigation strategies are not implemented (Paerl \& Otten, 2016). HABs require immediate attention from everyone who utilizes and relies on aquatic ecosystems, otherwise these compound effects will have substantial, irreversible consequences. 


\section{CHAPTER VI: LIMITATIONS}

There were numerous limitations throughout the duration of this research. First, the rapid development of the bloom resulted in a haste start of the research, with minimal time to fully develop a thorough research design. Second, lack of supplies, specifically bottles, and weather prevented samples from being collected every continuous day of the bloom. If there had been more samples there would have been more data to contribute to the final results, and could have explained some of the outliers in the dataset. Third, complications caused by the pandemic resulted in a loss of samples before further testing could be done. This included a PCR test, nutrient testing, and redoing ELISA tests. If a sample had a toxin concentration higher than $5 \mu \mathrm{l} / \mathrm{L}$, the test required those solutions to be diluted down to receive a more precise, accurate concentration. These elements would have added to the research in profound ways, however, once the samples were contaminated, there was no way to perform these tests. 


\section{REFERENCES}

Anderson, D. M., Gilbert, P. M., \& Burkholder, J. M. (2002). Harmful Algal Blooms and Eutrophication: Nutrient Sources, Composition, and Consequences. Estuaries, 25(4), 704-726.

Bauer, M., Hoagland, P., Leschine, T. M., Blount, B. G., Pomeroy, C. M., Lampl, L. L., Scherer, C. W., Ayres, D. L., Tester, P. A., Sengco, M. R., Sellner, K. G., \& Schumacker, J. (2010). The Importance of Human Dimensions Research in Managing Harmful Algal Blooms. Ecological Society of America, 8(2), 75-83.

Burford, M., Carey, C., Hamilton, D., Huisman, J., Paerl, H., Wood, S., \& Wulff, A. (2020). Perspective: Advancing the research agenda for improving understanding of cyanobacteria in a future of global change. Harmful Algae, 91, 101601.

Carmichael, W. (2008). A world overview-One-hundred-twenty-seven years of research on toxic cyanobacteria-Where do we go from here? Cyanobacterial harmful algal blooms: State of the science and research needs, 105-125.

Clark, J. M., Schaeffer, B. A., Darling, J. A., Urquhart, E. A., Johnston, J. M., Ignatius, A. R., Myer, M. H., Loftin, K. A., Werdell, J., \& Stumpf, R. P. (2017). Satellite Monitoring of Cyanobacteria Harmful Algal Bloom Frequency in Recreational Waters and Drinking Water Sources. Ecological Indicators, 80, 84-95.

Codd, G. A., Lindsay, J., Young, F. M., Morrison, L. F., \& Metcalf, J. S. (2005). Harmful Cyanobacteria. In J. Huisman, H. C. P. Matthijs, \& P. M. Visser (Eds.), Harmful Cyanobacteria (pp. 1-23). Springer Netherlands. https://doi.org/10.1007/1-4020-3022$\underline{31}$

Collen, B., Whitton, F., Dyer, E. E., Baillie, J. E. M., Cumberlidge, N., Darwall, W. R. T., Pollock, C., Richman, N. I., Soulsby, A.-M., \& Böhm, M. (2014). Global patterns of freshwater species diversity, threat and endemism. Global Ecology and Biogeography, 23(1), 40-51. https://doi.org/https://doi.org/10.1111/geb.12096 
EPA. (2015). A Compilation of Cost Data Associated with the Impacts and Control of Nutrient Pollution.

EPA. (2020). Harmful Algal Blooms \& Drinking Water Treatment. Retrieved April 3, 2021 from https://www.epa.gov/water-research/harmful-algal-blooms-drinking-water-treatment

Ford, W. I., Fox, J. F., Mahoney, D. T., DeGraves, G., Erhardt, A., \& Yost, S. (2020). Backwater Confluences of the Ohio River: Organic and Inorganic Fingerprints Explain Sediment Dynamics in Wetlands and Marinas. American Water Resources Association, 55(4), 692771.

Gatz, L., \& Library of Congress. Congressional Research, S. (2018). Freshwater harmful algal blooms : causes, challenges, and policy considerations. Report / Congressional Research Service ; R44871, 1 online resource. https://purl.fdlp.gov/GPO/gpo110162

https://crsreports.congress.gov/product/details?prodcode=R44871

Gilbert, P. M., \& Burford, M. A. (2017). Globally Changing Nutrient Loads and Harmful ALgal Blooms: Recent Advances, New Paradigms, and Continuing Challenges. The Oceanography Society, 30(1), 58-69.

Gorham, P. R. (1964). Toxic Algae as a Public Health Hazard. Journal - American Water Works Association, 56(11), 1481-1488. https://doi.org/10.1002/j.1551-8833.1964.tb01355.x

Gorham, T., Jia, Y., Shum, C. K., \& Lee, J. (2017). Ten-Year Survey of Cyanobacterial Blooms in Ohio's Waterbodies Using Satellite Remote Sensing. Harmful Algae, 66, 13-19.

Harke, M. J., Steffen, M. M., Gobler, C. J., Otten, T. G., Wilhelm, S. W., Wood, S. A., \& Paerl, H. W. (2016). A review of the global ecology, genomics, and biogeography of the toxic cyanobacterium, Microcystis spp. Harmful Algae, 54, 4-20.

Ingram, W. M., \& Prescott, G. (1954). Toxic fresh-water algae. American Midland Naturalist, 7587.

Lopez, C., Dortch, Q., Jewett, E., \& Garrison, D. (2008). Scientific assessment of marine harmful algal blooms.

Lopez, C., Jewett, E., Dortch, Q., Walton, B., \& Hudnell, H. (2008). Scientific assessment of freshwater harmful algal blooms. 
Meissner, S., Steinhauser, D., \& Dittmann, E. (2015). Metabolomic analysis indicates a pivotal role of the hepatotoxin microcystin in high light adaptation of $\mathrm{M}$ icrocystis.

Environmental microbiology, 17(5), 1497-1509.

Meneely, J. P., \& Elliott, C. T. (2013). Microcystins: measuring human exposure and the impact on human health. Biomarkers, 18(8), 639-649.

Miltner, R. J. (2018). Eutrophication Endpoints for Large Rivers in Ohio, USA. Environ Monit Assess, 190(55), 1-17.

Newman, C. W. (1979). Ohio River Navigation: Past-Present-Future.

Opp, S. M., \& Saunders, K. L. (2013). Pillar talk: local sustainability initiatives and policies in the United States-finding evidence of the "three E's": economic development, environmental protection, and social equity. Urban Affairs Review, 49(5), 678-717.

ORSANCO. (2021). Harmful Algal Blooms. Ohio River Valley Water Sanitation Commission. http://www.orsanco.org/data/harmful-algae-bloom-data/

Paerl, H. W., \& Otten, T. G. (2013). Harmful Cyanobacterial Blooms: Causes, Consequences, and Controls. Microbial Ecology, 65(4), 995-1010.

Paerl, H. W., \& Otten, T. G. (2016). Duelling 'CyanoHABs': unravelling the environmental drivers controlling dominance and succession among diazotrophic and non-N2-fixing harmful cyanobacteria. Environmental microbiology, 18(2), 316-324.

Sellner, K. G., Doucette, G. J., \& Kirkpatrick, G. J. (2003). Harmful Algal Blooms: Causes, Impacts, and Detection. J Ind Microbiol Biotechnol, 30, 383-406.

[Record \#152 is using a reference type undefined in this output style.]

Tisdale, E. S. (1931). COMBATING TASTES IN WEST VIRGINIA WATER SUPPLIES IN 1930. Journal (American Water Works Association), 23(9), 1357-1365.

Urquhart, E. A., Schaeffer, B. A., Stumpf, R. P., Loftin, K. A., \& Werdell, P. J. (2017). A Method for Examining Temporal Changes in Cyanobacterial Harmful Algal Bloom Spatial Extent Using Satellite Remote Sensing. Harmful Algae, 67, 144-152.

Vos, R. O. (2007). Defining sustainability: a conceptual orientation. Journal of Chemical Technology \& Biotechnology: International Research in Process, Environmental \& Clean Technology, 82(4), 334-339. 
Watanabe, M. F., \& Oishi, S. (1985). Effects of environmental factors on toxicity of a cyanobacterium (Microcystis aeruginosa) under culture conditions. Applied and Environmental microbiology, 49(5), 1342-1344.

Weber, S. J., Mishra, D. R., Wilde, S. B., \& Kramer, E. (2020). Risks for Cyanobacterial Harmful Algal Blooms Due to Land Management and Climate Interactions. Science of the Total Environment, 703, 1-14.

Wehr, J. D., \& Descy, J. P. (1998). Use of phytoplankton in large river management. Journal of Phycology, 34(5), 741-749.

Wehr, J. D., \& Thorp, J. H. (1997). Effects of Navigation Dams, Tributaries, and Littoral Zones on Phytoplankton Communities in the Ohio River. Can. J. Fish. Aquat. Sci., 54, 378-395.

Wells, M. L., Trainer, V. L., Smayda, T. J., Karlson, B. S. O., Trick, D. M., Kudela, R. M., Ishikawa, A., Bernard, S., Wulff, A., Anderson, D. M., \& Cochlan, W. P. (2015). Harmful Algal Blooms and Climate Change: Learning from the Past and Present to Forecast the Future. Harmful Algae, 49, 68-93. 


\section{CURRICULUM VITA}

Bevin Hardy

University of Louisville

Urban and Public Affairs

$426 \mathrm{~W}$ Bloom St

Louisville, KY, 40208
Email: bevin.hardy@louisville.edu

Phone: (865) 441-5265

\section{Education}

M.S Sustainability, University of Louisville, University Fellow

2019-Present

GPA: $3.96 / 4.00$

Advisor: Dr. Tamara Sluss

Thesis: Harmful Algal Blooms in the Ohio River

B.S. Environmental Studies, University of Tennessee, Knoxville

2014-2018

GPA: $3.69 / 4.00$

Minor: Anthropology, University of Tennessee, Knoxville

Advisor: Dr. Michael McKinney

\section{Research and Professional Experience}

\section{Louisville Community Grocery Outreach Intern}

2020 - Present

Work on monthly newsletter and social media outreach for new cooperative opening in a food desert in Louisville, KY

Farmers Market Manager, Bardstown Road Farmers Market 2020 - Present Manage and organize market operations and coordinate events weekly for the market

Harmful Algal Bloom Thesis, University of Louisville, PI: Dr. Tamara Sluss 2019 Present

Collected water samples throughout Harmful Algal Blooms (HAB) in the Fall of 2019, and analyzed toxin concentrations through ELISA tests in the lab

Fish and Wildlife Service Intern, Americorps and Student Conservation Association 2018

Worked as a natural resource intern performing plant surveys and harvesting native seed 
Hemlock Woolly Adelgid (HWA) Lab, UTK, PI: Dr. Christy Leppanen 2017 - 2018 Worked with a group of students to collect data about the infestation of HWA, and on media review based on how HWA is represented in the media resulting in a peer-reviewed publication

Asian Clam Independent Research, UTK, PI: Dr. Michael McKinney $2017-2018$ Designed project to tag and track Asian Clam movements in urban creates throughout Knoxville

UT Recycling Center Outreach Intern, UTK $2017-2018$ Worked on various projects including leading zero-waste events, organizing recycling Campus-wide, and forming outreach events

Urban Wilderness Survey, UTK, PI: Dr. Michael McKinney 2017 Created stakeholder survey for visitors at local urban wilderness centers to see whom the stakeholders were in Ijams, Forks of the River, etc.

Anthropology Lab, UTK, PI: David Anderson 2017 Worked on various projects regarding the excavation at Topper Hill; including: identifying ceramic finishes, mapping in GIS, and classifying different artifacts

Forensic Anthropology Center Volunteer, UTK, PI: Dawnie Wolfe Steadman 2014 Worked on cleaning recovered bones from excavated body donations

\section{Grants and Awards}

University Fellowship, University of Louisville-2019-2021 $\$ 30,000$ M.S. students with "prior research experience" and "exceptional credentials"

Geology Outstanding Graduate Award, University of Tennessee, Knoxville $\quad \$ 400$ Award to one exceptional geology graduate

Geology Professional Promise Award, University of Tennessee, Knoxville (2017) \$250 Awarded to one geology student that "displays qualities indicative of future success"

Dean's List Recipient (4), University of Tennessee, Knoxville (2014-2018) Students with a semester GPA greater than 3.50

Hope Scholarship, University of Tennessee, Knoxville (2014-2018) $\$ 12,000$ Students with exceptional academic record and achievements 


\section{Teaching Experience}

Guest Lecturer, Conservation Biology (BIOL 567/667)

2020

Title: The Intricacies of Conservation Biology in a Changing Climate

\section{Academic Presentations}

Ohio River Basin Symposium and Summit (Session Presenter)

2020

"Harmful Algal Blooms (HABs) in the Ohio River"

University of Tennessee, Knoxville EURēCA Research Symposium (poster) 2018

"Frequency of Hemlock Woolly Adelgid Information Provided in the Media:

Impacts, Ecology, and Citizen Outreach.

\section{Publications}

Leppanen, C., Frank, D. M., Lockyer, L. J., Fellhoelter, C. J., Cameron, A. K., Hardy, B. A., Smith, L. J., Smith, L. J., Clevenger, M. R., and Simberloff, D. 2018. Media representation of hemlock woolly adelgid management risks: a case study of science communication and invasive species control. Biological Invasions, 21, 615-624.

\section{Research Interests}

Topics of Interest: food systems, environmental anthropology, political ecology, sustainable systems, displaced people, migration/movement, landless farmer movements

Geographic Areas of Interest: Somali resettlement areas in America and Europe, Somali refugee camps, urban food systems, Latin America, U.S.-Mexico Border region

\section{Graduate Anthropology Courses}

Food and Farm Movements: Course focused on engaging with food movements from the past and present; covered sustainable agriculture, food cooperatives, and landless farmer movements in South America (Fall 2019 - Dr. Lisa Markowitz)

Ecology, Politics, and Culture: Course focused on the different approaches of cultural anthropology; concentrated on environmental anthropology and political ecology (Fall 2019 - Dr. Angela Storey)

Nutritional Anthropology: Course focused on broad discussions within nutritional anthropology; covered socially constructed ideas of food practices, authenticity, and health and the culture surrounding why people do not eat (Fall 2020 - Dr. Christopher Tillquist)

Mobilities and Displacement: Course focused on the barriers associated with movement and the different ways people are displaced across the globe; covered the obstacles for 
im/migrants, different stages of migration, settler colonialism in Palestine, and sources of displacement (Fall 2020 - Dr. Julie Peteet)

Food Justice: (Spring 2020 - Dr. Lisa Markowitz)

Ethnographic Methods: (Spring 2021 - Dr. Angela Storey)

Community Service/Extracurricular Activites

New Roots Volunteer $2019-2020$

Non-profit organization working to increase access to fresh produce across Louisville; volunteered setting up fresh food stops, and interacting with community members around local, organic food

OxFam Club, University of Tennessee $2016-2018$ Club focused on food justice, and feeding local community; helped with meals on wheels and volunteered at a local community garden

Sustainability Club, University of Tennessee $2016-2018$ Club focused on spreading knowledge of sustainable practices across campus; Participated in climate marches and outreach events on UTK's campus

SPEAK Club $2016-2018$

Environmental club on the University of Tennessee's campus focused on implementing green practices throughout campus. Helped establish community garden on campus.

Study Abroad, Arcadia University in Rome, Italy 2016 Studied sustainability, Italian, and archeology

Volunteered with local food kitchen to help feed with homeless and Refugee population. 